\title{
SLAVENSKE ETIMOLOGIJE
}

Ne nalazeći zadovoljavajuć ih etimologija riječi unutar indoevropske jezične porodice, možemo potražiti rješenje van nje. Nostratička lingvistika koja se bavi srodstvom semitohamitskih, kartvelskih, indoevropskih, uralskih, dravidskih, altajskih i drugih jezika - pruža nam nove mogućnosti. Vanindoevropskim materijalom V.M. Illič-Svityč protumačio je porijeklo npr. sl. *da čestica, *ščekot ซ /skokot " "škakljanje", lit. angà "otvor", latv. dijal. diñgt "biti mirnim, svladavati se", het. le "ne!" itd. 1

U ovoj bilješki objasnit ću na drugi način nego što se to prije činilo sl. *bokr, polj. baczyé i hrv. kaj. pözöj.

1. Slavenska riječ *bokb (stsl. bokъ, hs. bôk, bôka, slov. bòk, bóka češ, bok, slovin. bùek, rus. bok, ukr. bik, bóku itd). nema zadovoljava-

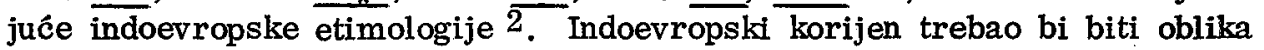
*boK- ili*baK- (gdje je $*_{K}-*_{\mathrm{K}} \mathrm{ili} *_{\mathrm{k}}^{\mathrm{W}}$ ), a taj je usporediv s ovim neindoevropskim korijenima:

semh. kuš. *ba(k) $\mathrm{k}^{\mathrm{W}}-$ "trbuh, bok" : afar bagu "trbuh, srce" somali bog, bug "trbuh, bok, srce", isak bóg "bok", digil bag "trbuh", bajso bo gi, isto, oromo buke "bok, strana, pored" ${ }^{3}$ (očekivalo bi se $* k^{\mathrm{W}}$ mjesto ${ }_{*_{\mathrm{k}} \mathrm{W}}$, no ima više primjera takve zasad neobjašnjene deglotalizacije u semitohamitskom);

kart. *baqw- "bedro, unutarnja strana bedra" u gruz. bagwi ${ }^{4}$;

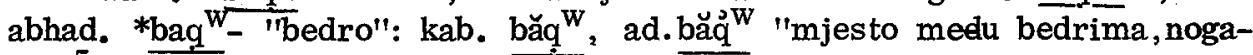
ma ${ }^{\prime \prime 5}$,

$1 \quad$ Illič-Svityč 1971,1976

2 ÉSSJa 2.170

3 Dolgopol'skij 1973:270

4 Klimov 1969:289, kart. +abhad.

5 Šagirov 1977:73 
nahdag. *bağ/bag "bok": bež. bel'ejo; lezg. ppag", agul. bay, rutul. beg, cahur. mugul, arč. bak ${ }^{\mathrm{w}}$, kryc. beg, hinal. bugra ${ }^{6}$;

? turk.: t. bögür "bok";

tungmandž. *bōk- "bedro" : evenk. bōkan, udej. b̄o, mandž. buxi; 7

? jap. bō "strana, bok" 8 .

Po tim podacima najverojatnija bi bila rekonstrukcija nostratičkog korijena *bagU "bok, bedro". No kako predindoevropski odstranjuje komplekse zvučni + bezvučni glotalizirani u korijenu, to je *bagU dalo *pagU, a to *b [a]$\mathrm{k}^{\mathrm{W}}$ - . No moguc je $\mathrm{i}$ refleks ${ }^{*} \mathrm{p}[\mathrm{a}] \mathrm{k}^{\mathrm{W}}-$, a takav se nalazi $\mathrm{u}$ ovim indoevropskim primjerima:

stind. pákșa- m. "rame, krilo"; pákșas-n. "strana, bok"; lat. pectus "grudi", latv. paksis "ugao u kuci"; toh. A. päśs̈äm, B. päścane "grudi"; s dugim vokalom: stind. pājasyá- n. "Bauchgegend, Weichen", rus. pax "prepona, slabina", paxa "pazuha" 9; no zanimljivi su primjeri s palatalom: stind. pājah "grudi, površina, lice", mladoavest. *pāzah, hotsak. pāysa- "lice", oset. faz, fazä "strana, polovina" (fazzon "blizanac"), faxs "bok, strana", zaza pize "trbuh", vahan.pōz "naručje", sangliči puz "grudi", jazg. pez isto, šugni pozēc "koža s trbuha životinje", hovari pāz "grudi"; lat. pāgina "list, strana"; sl. *pazuxal "grudi; prostor između grudi i odjeće" itd. 10 .

2. Iako je za poljski glagol baczyc "vidjeti, gledati, zamijetiti", st. "razmišljati, misliti, provjeravati, pamtiti, zaključivati, znati" (> ukr. báčyty "vidjeti", brus, báčyc, slč. báčiti se) dana vrlo uvjerliva etimologija kao *ob- + ${ }^{*}$-ačiti $<{ }^{*} \mathrm{ok}^{\mathrm{W}}-<{ }^{*} \mathrm{ok}^{\mathrm{W}}-{ }$ "oko" te se uspoređuje s iran. *abi-axšaya- u av. aiwyāxšaya- "promatrati, čuvati", horezm. $\beta$ ( ')yxy"učiti se", jagnobi yaxš- "vidjeti se, biti vidljiv" 11 - ipak valja ukazati na vanindoevropske primjere $s$ kojima bi taj poljski glagol mogao biti srodan.

6 SILDJa $103-4$

7 SSTMJa 1.90

8 Fel'dman-Konrad 1977:289

9 Pokorny 1. 792: (*peg-:) *pog-: * ${ }^{*} \overline{o g}-, *^{*} \overline{p o g}-\mathrm{s}-$. Sudeći po vanindoevropskom materijalu, radi se o $*$ p $[a] \mathrm{k}^{\mathrm{w}_{-}}$.

10 Paxalina 1975:236; Toporov 1972:37 i dalje gdje su i ostali indoevropski primjeri povezani s navedenima. Toporov ima *päǵ-/pēg-. Nejasno porijeklo *g. Gluhak 1977:50,54 bez *p[a]ǵg-。

11 Trubačev 1967:44-6 
V.M. Illič-Svityč ima nostratički korijen *baKa "gledati" rekonstruiran po semh. *blk - isto (arap. bqr "slijediti, osmatrati", stehbr. biqqēr "pažljivo izučavati", biqqēš "tražití"; berb. kabil. a abgu "željeti": somali bāg

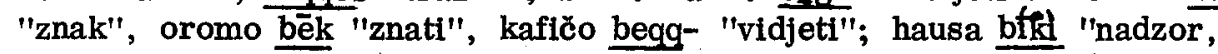
briga") te po altaj. *baka- "gledati" stujg. bak-, t.bak-.; mandž. baxa"shvatiti")12. Indoevropski bi refleksi tog nostratičkog korijena bili $\overline{*_{b}[a] k-}$ i * p[a]k - te bi se slavensko *obačiti odraženo u poljskom baczyé moglo protumačiti i kao *ob-b[a]k-i- - (T<*eje).

3. Hrv. kaj. pōzôj "zmaj", slov. pozoj isto izvodi se obično od glagola (u hs). zjằti, zjâm, zìjati, zijām (atsl. zijajọ) kao što je hs. loj došlo od liti ${ }^{13}$. U riječima zmija, zmaj krije se isti korijen koji i u riječi zemlja. Isti se korijen nalazi i u riječi pozoj.

U ie. *dhğhem- "zemlja" (stind.kssam-, het. tekan, grč.khthốn, alb. dhe, lat. humus, stir. dú, lit. žêmé, stsl. zemlja, toh. A tkam̉, B kem) *-emjest sufiks; u prilog tome govori kartvelski korijen *diga "zemlja, glina" (stgruz. diqa "zemlja, blato", gruz. tixa, can. (n)dixa, megrel. dixa, dexa) $s$ kojim je povezano ie. *dhǵem- ${ }^{14}$. Ie. *dhgh- može se objasniti od

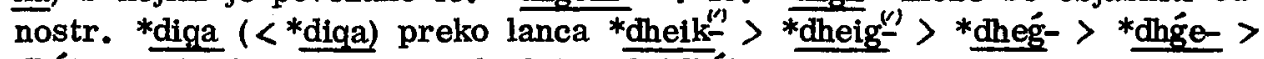
dhǵhe-. Sl. *zojb po tome bi bilo od *dhğhoi-.

\section{Literatura}

Dolgopol'skijj A. B. 1973. Sravnitel'no-istoričeskaja fonetika kušitskix jazykov. Moskva, Nauka.

ÉSSJa 2, 1975. Ėtimologičeskij slovár slavjanskix jazykov. Praslavjanskjj leksičeskij fond. Vypusk 2 (*bez-*bratrz). Pod red O.N. Trubačeva. Moskva, Nauka.

Fel'dman-Konrad N.I. 1977. Japonsko-russkij učebnyj slovár leroglifov. Izd. 20e. Moskva, Russkij jazyk.

Gluhak A. 1977. Nostratica. Suvremena lingvistika 15-16, str. 49-56. Zagreb, Institut za lingvistiku Filozofskog fakulteta.

12 Illič-Svityč 1971:172-3, semh.+alt.

13 Skok 3.658

14 Illič-Svityč 1971:220, kart. + ie. 
Illič-Svityč V.M. 1971-76. Opyt sravnenija nostratičeskix jazykov (semitoxamitskij, kartvel'skij, indoevropskij, ural'skij, dravidijskij, altajskij). I-II. Moskva, Nauka.

Klimov G.A. 1969. Abxazoadygsko-kartvel'skie leksičeskie paralleli. Étimologija 1967, 286-95. Moskva, Nauka.

Paxalina T.N. 1975. Vaxanskij jazyk. Moskva, Nauka.

Pokorny J. 1959-69. Indogermanisches etymologisches Wörterbuch. I-II. Band. Bern und München, Francke Verlag.

SILDJa 1971. Sravnitel 'no-istoričeskaja leksika dagestanskix jazykov. Moskva, Nauka.

Skok P. 1971-74. Etimologijski rječnik hrvatskoga ili srpskoga jezika. I-IV. Zagreb, Jugoslavenska akademija znanosti i umjetnosti.

SSTMJa 1, 1975. Sravnitel'nyj slovaŕ tunguso-mańčžurskix jazykov. Materialy $\mathrm{k}$ étimologičeskomu slovarju. Tom. I, A-N. Leningrad, Nauka LO.

Šagirov A.K. 1977. Ėtimologičeskij slovaŕ adygskix (čerkesskix) jazykov. A-N. Moskva, Nauka.

Toporov V.N. 1972. O proisxoždenii neskol'kix russkix slov.(K svjazam $\mathrm{S}$ indo-iranskimi istočnikami). Ėtimologija 1970, 21-45. Moskva, Nauka.

Trubačev O.N. 1967. Iz slavjano-iranskix leksičeskix otnošenij. Étimologija 1965, 3-81. Moskva, Nauka.

\section{S U M MA RY}

\section{SLAVIC ETYMOLOGIES}

The author considers that if it is not possible to find satisfying etymology inside the Indo-European family, we must seek out of it. He gives these examples: Sl. *boks "flank, thigh", Pol.baczyc "to look, to see, to observe", Croat. and Slov. pozoj "dragon" might belong to Nostratic roots *bagU "flank, thigh", *baKa "to look", and *diga "ground" (reflected in IE *dhǵhemtoo) respectively. 